\title{
UNA O MÚLTIPLES
}

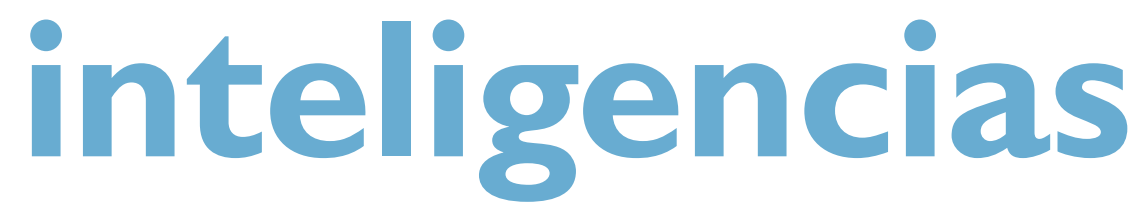

DOI

http://dx.doi.org//0.14422/pym.v0i357.3290

Francisco Rodríguez Santos

Director de la Unidad de Evaluación y Diagnóstico Neuropsicológico UDEN-EOS

Profesor asociado de Psicología UAM

frodriguez@cop.es

a inteligencia ha sido considerada una capacidad para la resolución de tareas complejas. Al principio, se creía que era una habilidad que se tenía o no; pero poco a poco se fue introduciendo la idea de gradación, de algo que se deba en mayor o menor medida.

La idea de unicidad fue cambiándose por la presencia de una inteligencia más verbal y otra más manipulativa o visoespacial. Al mismo tiempo, en especial en la selección de personal, fuera para el trabajo o el ejército, fue tomando fuerza la consideración de un conjunto de aptitudes que estarían directamente relacionadas con las actividades que debían realizar las personas: cálculo, razonamiento, relaciones públicas, organización. Este enfoque se fue introduciendo en la orientación educativa y vocacional y comenzaron a medirse aptitudes para la música, el estudio de la naturaleza, las humanidades, etcétera.

Así pues, el hecho de tener una buena inteligencia, reflejado en un buen expediente académico, no asegura el éxito futuro, por ejemplo cuando se trata de ser emprendedor o de saber cómo relacionarte socialmente.

\section{LAS INTELIGENCIAS MÚLtIPLES SEgúN GARDNER}

El psicólogo Howard Gardner, de la Universidad de Harvard, empezó a plantearse en el año 1983 que la inteligencia era una "capacidad mental para resolver problemas y/o elaborar productos en un medio ambiente sociocultural adecuado". Como tal capacidad, depende en alguna medida de las oportunidades que proporciona el ambiente a la persona y puede ser fomentada o desarrollada a través de la educación.

La inteligencia sería un "conjunto de inteligencias múltiples", diferentes y, aunque son interdependientes, también son diferentes entre sí.

Estas inteligencias reflejan la forma en que conocemos el mundo y se encuentran en todas las personas en mayor o menor grado, formando un perfil de puntos fuertes $y$ débiles para cada individuo.

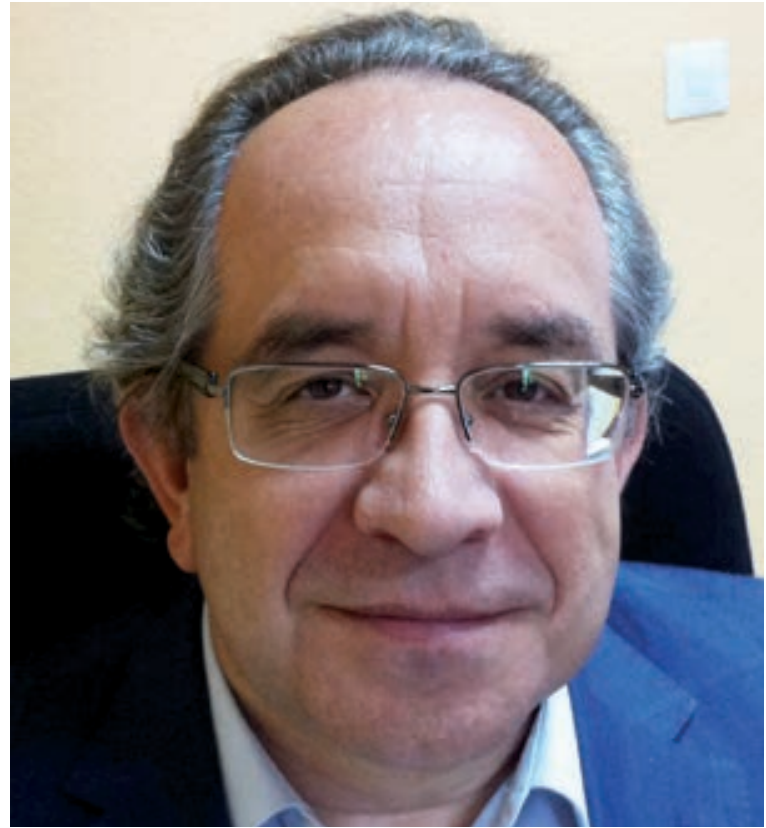

Francisco Rodríguez Santos. 


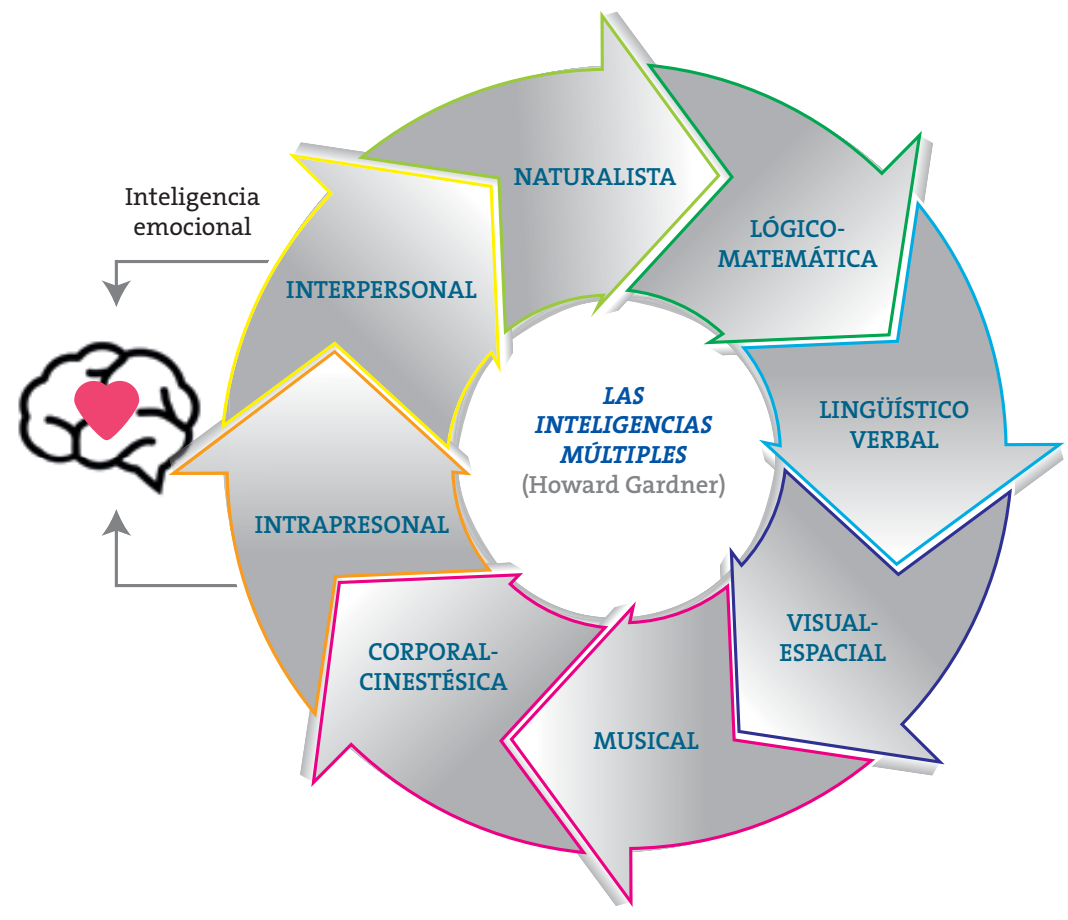

- Lógico-matemática: propia de los científicos, los matemáticos, pero también de los filósofos; permite pensar de forma lógica y crítica y establecer relaciones.

- Lingǘstico-verbal: es la que permite a los escritores, oradores y poetas desarrollar sus potencialidades; está relacionada con el aprendizaje de idiomas, la comprensión de metáforas y la expresión verbal, tanto oral como escrita. Junto a la lógico-matemática es la más fomentada en los sistemas educativos clásicos.

- Visual-espacial: presente en ingenieros, arquitectos, cirujanos, marineros...; permite generar imágenes mentales, comparar objetos, y relacionar colores y formas.

- Musical: es la más desarrollada en los músicos, relacionada con la percepción de los sonidos y la música, la creación y la reproducción de piezas musicales y ritmos.

- Corporal-cinestésica: además de en los bailarines y deportistas, está más desarrollada en los artesanos, cirujanos y todas aquellas personas que necesiten controlar sus movimientos, utilizar la coordinación motora fina o expresar emociones e ideas corporalmente.

- INTRAPERSonal: relacionada con el conocimiento de uno mismo, es la inteligencia de los filósofos, religiosos y todos aquellos que tienen un nivel de introspección y de meditación importante; permite tomar conciencia del yo, concentrarse y reflexionar sobre sí mismo.

- INTERPERSONAL: propia de los psicólogos, profesores, políticos y todos aquéllos que tiene buena capacidad para conocer a los demás, desarrollar la empatía, trabajar de forma cooperativa y las habilidades sociales.

- Naturalista: está presente en los biólogos, agricultores, geólogos...; está relacionada con el estudio y comprensión de la naturaleza, las plantas, los animales y la conciencia ambiental.

\section{OBTENIENDO INFORMACIÓN SOBRE LAS INTELIGENCIAS EN UN ALUMNO \\ La mayor parte de los niños muestran un equilibrio entre sus inteligencias $y$ algunos son especialmente bue- nos en una o varias de ellas. Pero, ¿cómo podemos saber cuáles son éstas? Podemos dividir los procedimientos para obtener información sobre cómo es el perfil del niño o la niña en tres tipos:}

- Observación: prestar atención a cuáles son las actividades que el niño realiza, en especial aquéllas que prefiere hacer en situaciones de ocio y tiempo libre, en el recreo, jugando, en los rincones cuando se le da a elegir, etcétera. También en las actividades extraescolares, cuáles son aquéllas que realiza con placer y sobre las que más habla.
- Entrevistas: se puede preguntar al maestro y a los padres sobre qué es lo que más le gusta, qué hace mejor, si tienen alguna habilidad especial o grupo de habilidades, a qué le dedica más tiempo, etcétera. Es importante también preguntarle al niño o la niña sobre qué es lo que le gusta o querría hacer.

- Cuestionarios y pruebas: los psicólogos educativos disponen de tests para valorar el perfil de inteligencias en el ámbito escolar, una parte de ellos requiere la aplicación de cuestionarios al alumnado.

Es posible que, durante la aplicación de las pruebas, aparezcan capacidades que el niño o la niña en su vida diaria no pone en marcha o no tiene la oportunidad de hacerlo. Uno de las medidas más apropiadas es 


\section{Caminando juntos}

Debemos fomentar la comunicación a través de la conversación con los hijos. Lo mejor es hacerlo a lo largo de la jornada, pero si se dispone de poco tiempo, hay que establecer un tiempo a la semana, por el ejemplo el sábado o domingo por la mañana, para describir al niño nuestras sensaciones, opiniones, etc., y permitirle que exponga las suyas. Nuestra propia intervención servirá como modelo del niño y debe evitarse criticar o ridiculizar al niño por sus ideas y se sugiere utilizar el diálogo como negociación, si es preciso.

proporcionar ocasiones para experimentar distintas actividades con diferentes materiales e instrumentos. Y, posteriormente, observar cómo se maneja la persona en dichas situaciones.

\section{FAVORECIENDO LAS INTELIGENCIAS MÚLTIPLES}

La actitud de los adultos, maestros y padres, tiende a reforzar aquellas actividades que a ellos se les dan bien - les gustaría haber podido aprender. Esto en sí, que permite que los menores a su cargo puedan experimentar diferentes opciones, también limita las oportunidades de los niños. Lo mejor es abrir todo un abanico de posibilidades, tanto en el contexto escolar como el familiar, a través de la educación reglada, el juego y las actividades extraescolares.

A continuación, proponemos algunas actividades para facilitar el desarrollo de las diferentes inteligencias:

- Lógico-matemática: en el contexto escolar se llevan a cabo tareas relacionadas con el cálculo y las matemáticas, no obstante, es menos frecuente que se utilicen dichos instrumentos en situaciones de la vida diaria; pero, los niños y las niñas, como físicos naturales realizan constantemente experimen-

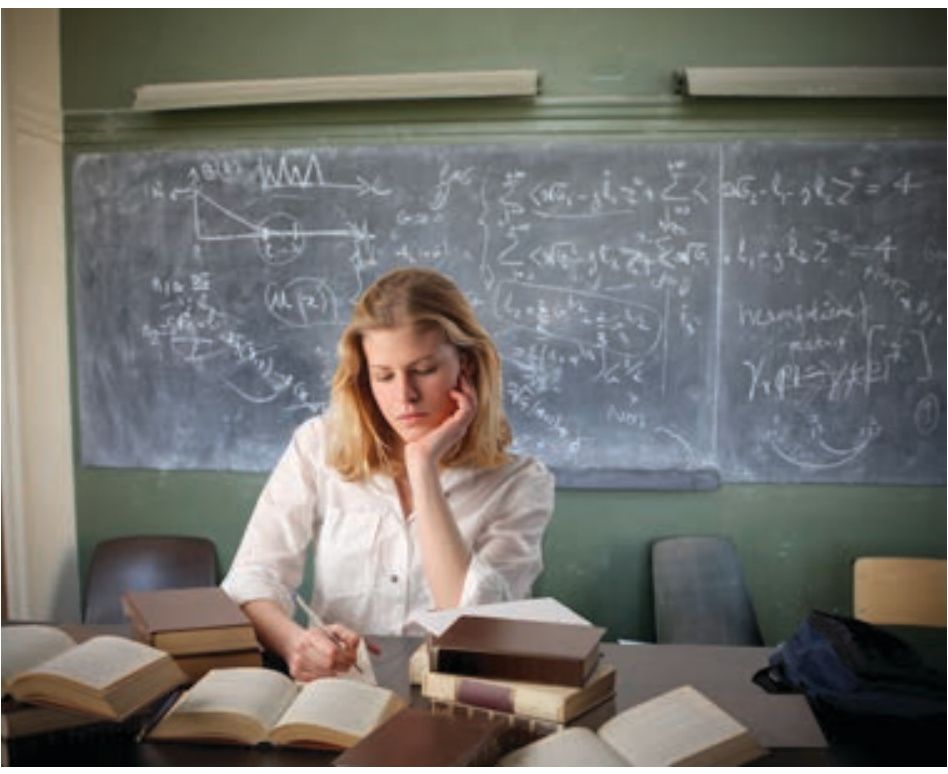

tos durante sus juegos, desafortunadamente, se va perdiendo esta tendencia del juego y se limita casi exclusivamente al contexto académico; se puede fomentar esta inteligencia con todo lo anterior, hacer pequeños experimentos, hacer interpretaciones de gráficos $y$, en definitiva, aplicar aquello que se aprende de forma abstracta a situaciones concretas de la vida cotidiana.

\section{la inteligencia para}

\section{Gardner es una capacidad} mental para resolver problemas y/o elaborar productos

\section{en un medio ambiente}

\section{sociocultural adecuado}

- Lingüístico-verbal: el aprendizaje de idiomas y la lectoescritura se encuentran dentro de la propuesta curricular de los centros educativos, sin embargo, con demasiada frecuencia dichos conocimientos no se utilizan en la vida diaria, no se ponen en práctica para lo que es su función más importante que es la comunicación, transmisión de ideas, de conocimientos, de sentimiento. Debería fomentarse la comunicación en todas sus formas aplicadas a la vida diaria $y$, en especial, a la conversación, dejar tiempos tanto en clase como en el hogar para conversar con los niños sobre temas de su interés y otros que pensemos que pueden llegar a gustarle.

- Visual-espacial: habitualmente a los niños les gusta dibujar y pintar, habría que darles la oportunidad de utilizar diferentes tipos de materiales para la creación, usando tanto modelos predeterminados como permitiendo la creación libre. Otra de las actividades que realizan los niños con frecuencia

\section{actividades de aula}

Con esta actividad se pretende trabajar distintos tipos de inteligencia en el siguiente orden: musical, intrapersonal, visoespacial, verbal-lingüística e interpersonal.

- Realizar una actividad de relajación con música y guiada por el adulto en la que el niño haya de imaginarse un paisaje. Posteriormente ha de describir a sus otros compañeros sus sensaciones de manera oral, así como el paisaje que se han imaginado. Hacer notar las diferencias entre ellos en cuanto a los relatos y lo que se han imaginado. Finalmente, pedirles que hagan una descripción escrita del paisaje y que lo dibujen para exponerlos en el aula. 
Identificar los objetivos educativos de las diferentes materias y relacionarlos con las inteligencias múltiples o competencias básicas. Proponer actividades educativas que permitan trabajar las inteligencias menos representadas en las distintas materias. Llevar a cabo proyectos de patio de recreo y actividades complementarias que faciliten dichas inteligencias.

son las construcciones, los rompecabezas, la manipulación de objetos, etcétera, pueden utilizarse distintos tipos de piezas, materiales, tamaños, colores y formas; menos frecuente es la realización de actividades que incluyan desarrollar la representación y orientación espacial, sea en el plano, con la elaboración de mapas, o en el espacio, con actividades de interpretación de dichos mapas y recorridos e incluso excursiones por espacios urbanos y el campo.

- Musical: la música y el ritmo forman parte del desarrollo de las capacidades cognitivas y lingüísticas en nuestra especie y son muy importantes para la evolución de los niños; excepto en la etapa infantil, la música se limita a una asignatura en el ámbito escolar, se deberían fomentar actividades para ejercitar esta inteligencia, tanto como materias optativas (música, canto, aprendizaje de instrumentos musicales diversos), como actividades extraescolares; por su parte, en el contexto familiar se debería permitir la audición de diferentes tipos de música y el uso de distintos instrumentos.

- Corporal-cinestésica: permitir que el niño se mueva, hay que enfrentarse a la idea general de que los niños han de comportarse como adultos y estarse quietos en clase y en casa; la realización de deportes, actividades de teatro, danza, juegos de movimiento y actividades de destreza manual, son buenas oportunidades para aprender a desarrollar esta inteligencia.

- Naturalista: el cultivo de pequeñas plantas y el cuidado de animales domésticos puede ser una buena oportunidad para desarrollar esta inteligencia; también pueden realizarse actividades al aire libre, observaciones del comportamiento de los animales, la recogida de materiales (minerales, insectos, plantas) y su catalogación, así como cultivar y hacer un seguimiento a lo largo del curso; finalmente, la con- cienciación por la conservación de la naturaleza, el reciclado, la racionalización del gasto energético, formarían parte de esta inteligencia.

- Intrapersonal: la identidad personal se desarrolla desde la identificación del propio esquema corporal hasta el conocimiento de las propias capacidades y puntos débiles; se podrían realizar actividades de descripción de historias personales, autobiografías, que cuenten que han hecho en el fin de semana o las vacaciones y llevar un diario personal; reconocer las propias emociones, sus creencias y opiniones respecto a diferentes temas, etcétera.

- Interpersonal: la metodología de aprendizaje cooperativo fomenta muchas habilidades relacionadas con esta inteligencia; debe permitirse a los niños aprender a resolver por sí solos situaciones conflictivas con los adultos e iguales, dándoles alternativas de solución y/o con la participación de otros alumnos como mediadores; el trabajo sobre historias o guiones sociales y, especialmente, la conversación y la negociación para llegar a acuerdos.

Podría darse la circunstancia de que una persona tenga una muy buena ejecución en un tipo de inteligencia, pero que no disfrute con las actividades que le proponemos para su desarrollo. Habría que analizar cuáles son variables que están condicionando esta situación: la falta de tiempo, otras actividades que le gustan más, pocas oportunidades, etc. Es muy importante sugerir pero no empeñarse en que al niño o a la niña ha de gustarle algo, que en realidad, no le gusta.

\section{Para saber más}

- Armstrong, T. (2006). Inteligencias múltiples en el aula. Barcelona: Paidós.

- Campbell L.; Campbell B., y Dickenson D. (2000). Inteligencias múltiples: usos prácticos para la enseñanza y el aprendizaje. Barcelona: Troquel.

- Gardner, H. (2005). Inteligencias múltiples: la teoría en la práctica. Buenos Aires: Paidós.

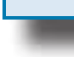

\section{hemos hablado de:}

Howard Gardner; inteligencias múltiples; intervención; evaluación.

Este artículo fue solicitado por PADRES Y MAESTROS en enero de 2014, revisado y aceptado en marzo de 2014 para su publicación. 